Article

\title{
Inhibition and Inactivation of Uropathogenic Escherichia coli Biofilms on Urinary Catheters by Sodium Selenite
}

\author{
Amoolya Narayanan ${ }^{1}$, Meera S. Nair ${ }^{2}$, Muhammed S. Muyyarikkandy 2 (D) \\ and Mary Anne Amalaradjou 2,* (iD) \\ 1 Department of Psychology, University of Connecticut, Storrs, CT 06269, USA; \\ amoolya.narayanan@gmail.com \\ 2 Department of Animal Science, University of Connecticut, Storrs, CT 06269, USA; \\ meera.nair@gmail.com (M.S.N.); muhammed.muyyarikkandy@uconn.edu (M.S.M.) \\ * Correspondence: mary_anne.amalaradjou@uconn.edu; Tel.: +1-860-486-6620; Fax: +1-860-486-4375
}

Received: 24 April 2018; Accepted: 5 June 2018; Published: 7 June 2018

check for updates

\begin{abstract}
Urinary tract infections (UTI) are the most common hospital-acquired infections in humans and are caused primarily by uropathogenic Escherichia coli (UPEC). Indwelling urinary catheters become encrusted with UPEC biofilms that are resistant to common antibiotics, resulting in chronic infections. Therefore, it is important to control UPEC biofilms on catheters to reduce the risk for UTIs. This study investigated the efficacy of selenium for inhibiting and inactivating UPEC biofilms on urinary catheters. Urinary catheters were inoculated with UPEC and treated with 0 and $35 \mathrm{mM}$ selenium at $37^{\circ} \mathrm{C}$ for 5 days for the biofilm inhibition assay. In addition, catheters with preformed UPEC biofilms were treated with $0,45,60$, and $85 \mathrm{mM}$ selenium and incubated at $37^{\circ} \mathrm{C}$. Biofilm-associated UPEC counts on catheters were enumerated on days $0,1,3$, and 5 of incubation. Additionally, the effect of selenium on exopolysacchride (EPS) production and expression of UPEC biofilm-associated genes was evaluated. Selenium at $35 \mathrm{mM}$ concentration was effective in preventing UPEC biofilm formation on catheters compared to controls $(p<0.05)$. Further, this inhibitory effect was associated with a reduction in EPS production and UPEC gene expression. Moreover, at higher concentrations, selenium was effective in inactivating preformed UPEC biofilms on catheters as early as day 3 of incubation. Results suggest that selenium could be potentially used in the control of UPEC biofilms on urinary catheters.
\end{abstract}

Keywords: UPEC; selenium; biofilm; urinary catheters; exopolysaccharide; gene expression

\section{Introduction}

Urinary tract infection (UTI) is one of the most common infections in humans, accounting for more than 150 million cases worldwide [1]. In the U.S., approximately 11 million cases of UTIs are reported each year with associated costs estimated to be $\$ 5$ billion annually [2]. In addition to being the most common bacterial infection, UTIs also account for $36 \%$ of all health-care associated infections (HAI; [3]). Of these 36\% infections, $80 \%$ of them are estimated to be catheter-associated $[3,4]$. In fact, catheter-associated urinary tract infections (CAUTIs) are the most common HAI in the United States, accounting for 1 million cases each year [5,6]. According to the Centers for Disease Control and Prevention (CDC), a CAUTI is defined as a UTI in a patient who had an indwelling urinary catheter in place at the time or within $48 \mathrm{~h}$ prior to infection [7]. Beyond the initial urinary infection, CAUTIs can lead to complications including bacteremia, endocarditis, osteomyelitis, septic arthritis, and meningitis [4]. These pathologies collectively result in prolonged hospital stays and increased morbidity and mortality $[8,9]$. 
The susceptibility of an individual to CAUTI is mediated by several risk factors, including older age, female gender, diabetes, and impaired immunity $[9,10]$. However, the most important risk factor is the use of an indwelling catheter and the duration of catheterization [9,11]. The CDC estimates that approximately $12-16 \%$ of adult hospital inpatients will have an indwelling catheter at some point during their hospitalization and that the risk for developing a CAUTI increases by $3-7 \%$ with each additional day of catheterization [7]. This increased susceptibility in catheterized patients is due to the ability of the catheter to bypass several host defenses and thereby enable bacterial entry into the urinary tract [12]. In intubated patients, bacteria can ascend from the urethral meatus into the bladder by migrating between the mucosal and catheter surfaces. Further, contamination of the drainage bag or disruption in the tubing junction may also result in bacterial migration via the drainage system [4]. Additionally, the presence of an indwelling device favors the persistence of the etiological agent in the urinary tract, thereby increasing the risk for CAUTI [13].

UTIs, including CAUTIs, can be caused by several bacterial species, including uropathogenic Escherichia coli (UPEC), Staphylococcus saprophyticus, Klebsiella pneumoniae, Enterococcus faecalis, group B Streptococcus, Staphylococcus aureus, Proteus mirabilis, Pseudomonas aeruginosa, and Enterobacter spp. [9,14]. However, the most common causative agent for UTI and CAUTI is UPEC. It is estimated that UPEC is responsible for approximately $80 \%$ of all UTIs $[9,14]$. This high incidence of infections associated with UPEC can be attributed to the repertoire of virulence factors that each UPEC strain possesses $[1,4]$. These factors, which are critical to establishing a successful infection, include adhesins, toxins, surface polysaccharides, flagella, iron acquisition systems, immune evasion, and biofilm formation [1,9]. In case of CAUTI, the ability of the pathogen to adhere and form biofilms on the indwelling medical device results in persistent and recurrent infections in catheterized patients $[4,15,16]$.

In order to form a biofilm, the pathogen must first adhere to the medical device long enough to facilitate permanent attachment. In case of catheters, this adhesion and attachment is favored by the deposition of proteins and polysaccharides from the urine on to the device surface. Once the bacteria are permanently attached to the catheter surface, they produce exopolysaccharides to from the biofilm. Several studies have demonstrated the presence of adherent biofilms on catheters removed from patients with CAUTI [17-19]. Besides providing them with the ability to persist in an environment, once encased in a biofilm, pathogens are protected from environmental conditions, antibiotic therapies, and the host's immune system $[15,20]$. As with other bacterial infections, antibiotics are the current therapeutic agents of choice in controlling CAUTIs. However, given the inherent resistance of a biofilm to antimicrobial agents and the increase in rates of antibiotic resistance, alternative therapies are warranted [9]. Therefore, the present study investigated the potential application of a dietary mineral, namely selenium, in controlling UPEC biofilms on catheters.

Selenium (Se) is a well-recognized dietary antioxidant, and its compounds are commonly used in nutrition and chemoprevention therapy [21]. It is an essential component of several enzymes, including glutathione reductase, and is recommended for daily dietary intake in humans by the Food and Drug Administration (FDA) with an upper tolerable intake level of 400-800 $\mu \mathrm{g}$ [22]. Several selenium-based formulations, such as selenomethionine and sodium selenite $\left(\mathrm{Na}_{2} \mathrm{SeO}_{3}\right)$, are available commercially as food supplements, anticancer agents, and immune stimulators. Although widely known for its antioxidant properties, selenium as an antibacterial agent is a novel compound that has not been widely explored [23]. There are a few studies that have investigated the antibacterial potential of selenium and its compounds. Vasic et al. [24] demonstrated the ability of sodium selenite to alter the growth dynamics and extracellular protein synthesis in Bacillus subtilis, Bacillus mycoides, E. coli, and Pseudomonas spp. The study also showed that sodium selenite increased the inhibitory effect of antibiotics for all tested bacteria in liquid culture. Similarly, Kumar et al. [25] observed an anti-ulcer and antibacterial activity in rats infected with Helicobacter pylori. Further, Alam et al. [26] demonstrated that sodium selenite exhibited a strong spectrum of activity against planktonic cells of Bacillus subtilis, Staphylococcus aureus, Escherichia coli, and Klebsiella planticola. Furthermore, biosynthesized Se nanoparticles were found to be inhibitory to foodborne pathogens, including Bacillus cereus, Enterococcus faecalis, S. aureus, E. coli 
O157:H7, S. typhimurium, and S. enteritidis $[27,28]$. Although these studies demonstrate the antibacterial activity of selenium, to the best of our knowledge and based on a survey of current literature, there is no report on the antibiofilm effect of sodium selenite. Consequently, this study investigated the efficacy of sodium selenite in inhibiting UPEC biofilm formation and inactivating mature biofilms on urinary catheters. Further, the effect of selenium on the expression of virulence genes essential for UPEC adhesion and biofilm formation was studied.

\section{Results and Discussion}

The sub inhibitory concentration (SIC), minimum inhibitory concentration (MIC), and MBC minimum bactericidal concentration (MBC) of selenium against UPEC was $35 \mathrm{mM}(0.6 \%), 60 \mathrm{mM}(1 \%)$, and $85 \mathrm{mM} \mathrm{(1.5 \% ),} \mathrm{respectively.} \mathrm{Since} \mathrm{selenium} \mathrm{was} \mathrm{found} \mathrm{to} \mathrm{be} \mathrm{equally} \mathrm{effective} \mathrm{in} \mathrm{inhibiting} \mathrm{and}$ inactivating UPEC biofilms in both tested strains $(p>0.05)$, only results observed with E. coli CFT073 are presented in the manuscript unless mentioned otherwise.

\subsection{Inhibition of UPEC Biofilm Formation on Urinary Catheters by Selenium}

Since the initial adhesion, attachment, and exopolysaccharide (EPS) production are critical to the establishment of a mature biofilm, compounds that inhibit the growth of bacteria have been routinely used to impair biofilm formation [29-33]. However, since these compounds may lead to selection for strains resistant to the antimicrobial, there has been an increasing interest in the use of agents that regulate biofilm formations without interfering with bacterial growth. Therefore, in the present study we investigated the ability of an SIC of selenium to inhibit biofilm formation as means to reduce the risk for biofilm-associated pathologies, including CAUTI. Since selenium is employed at the SIC, it is expected that the antimicrobial metal would inhibit biofilm formation by regulating the process and not by inactivating the organism.

As can be seen from Figure 2.1, incorporation of the SIC of selenium significantly inhibited biofilm formation when compared to the control $(p \leq 0.05)$. With the control samples $(0 \mathrm{mM} \mathrm{Se})$, on day 1 , approximately $5.5 \log$ CFU of biofilm-associated UPEC were observed. On the other hand, in the presence of $35 \mathrm{mM}$ selenium, UPEC counts in the biofilm were reduced to $\sim 3.45 \log \mathrm{CFU} /$ catheter, respectively. Further, by the end of the 5-day incubation, selenium treatments reduced the number of biofilm-associated bacteria by $3.5 \log$ when compared to the control ( $6.0 \log$ CFU/catheter). Similar results were observed when E. coli O157:H7 and Vibrio cholera were exposed to the SIC of selenium, manganese, and zinc $[34,35]$. Specifically, at $24^{\circ} \mathrm{C}$, the use of $30 \mathrm{mM}$ selenium was found to reduce the number of biofilm-associated $E$. coli $\mathrm{O} 157$ population by approximately $4 \log \mathrm{CFU} / \mathrm{mL}$ when compared to the control ( 8 $\log \mathrm{CFU} / \mathrm{m}$; [34]). Along these lines, Yang et al. [36] demonstrated that sub-MIC of Allicin, an essential oil in garlic, inhibited UPEC biofilm formation on a polystyrene matrix.

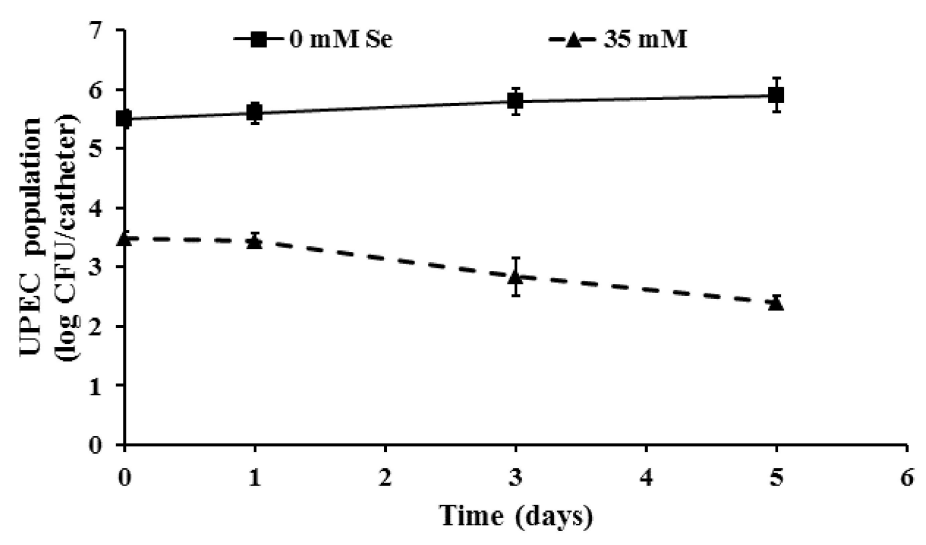

Figure 1. Inhibition of uropathogenic Escherichia coli (UPEC) biofilm formation on urinary catheters by selenium. 
Catheter pieces $(3 \mathrm{~cm})$ were inoculated with UPEC $(\sim 6.0 \log \mathrm{CFU})$ and incubated at $37^{\circ} \mathrm{C}$ in the absence and presence of a sub inhibitory concentration (SIC) of selenium for 5 days. Following $0,1,3$, and 5 days of exposure, the surviving cells in the biofilm were dispersed by sonication and enumerated. Data are represented as mean $\pm \mathrm{SEM}$. Treatments are significantly different from the control at $p \leq 0.05$.

\subsection{Effect of Selenium on EPS Production in UPEC Biofilms}

Bacterial cells within the biofilm are encased in an extracellular matrix (ECM) that helps to tenaciously bind the sessile cells to the underlying surface [32]. The ECM is highly hydrated and primarily composed of exopolysaccharides [4,32]. In addition to EPS, the matrix is also composed of proteins, DNA, lipids, glycolipids, and membrane vesicles $[5,15,37,38]$. Besides anchoring the biofilm to the underlying substrate, ECM is also essential to the integrity and function of the biofilm. Specifically, any defect in EPS synthesis and export can impair the formation of multilayer biofilms in most bacteria [39-41].

Given the significance of EPS to the structural integrity of the biofilm and our previous observation of the inhibitory effect of selenium on UPEC biofilm formation, we investigated the efficacy of the SIC of selenium to inhibit EPS production and thereby impair biofilm formation. As can be seen in Figure 2, exposure to the SIC of selenium significantly impaired EPS production by UPEC ( $p \leq 0.05)$. As early as day 1 of incubation, EPS production in the treatment was found to be reduced by greater than $60 \%$ when compared to the control. Further, the reduced ability to produce EPS was observed till the end of the 5-day study period with the selenium-treated samples. Additionally, this reduction in EPS production was concomitantly associated with a reduction in the number of biofilm-associated UPEC (Figure 2.1). On the other hand, with the control samples, there was an overall increase in EPS production with the maturation of the biofilm from day 1 to day 5 . Our results are in corroboration with previous findings that demonstrate that exposure of E. coli, K. pneumoniae, E. faecalis, S. aureus, and B. subtilis to turmeric extract resulted in a significant reduction in EPS production and associated biofilm formation [42]. Similarly, inclusion of $1 \%$ ginger extract was found to significantly reduce EPS production and biofilm formation by 40-69\% in P. aeruginosa PA14 [33]. Moreover, use of selenium (30 mM; SIC) has been recently shown to significantly reduce EPS production at $24^{\circ} \mathrm{C}$ in E. coli $\mathrm{O} 157$ by greater than $75 \%$ by $96 \mathrm{~h}$ of incubation [34].

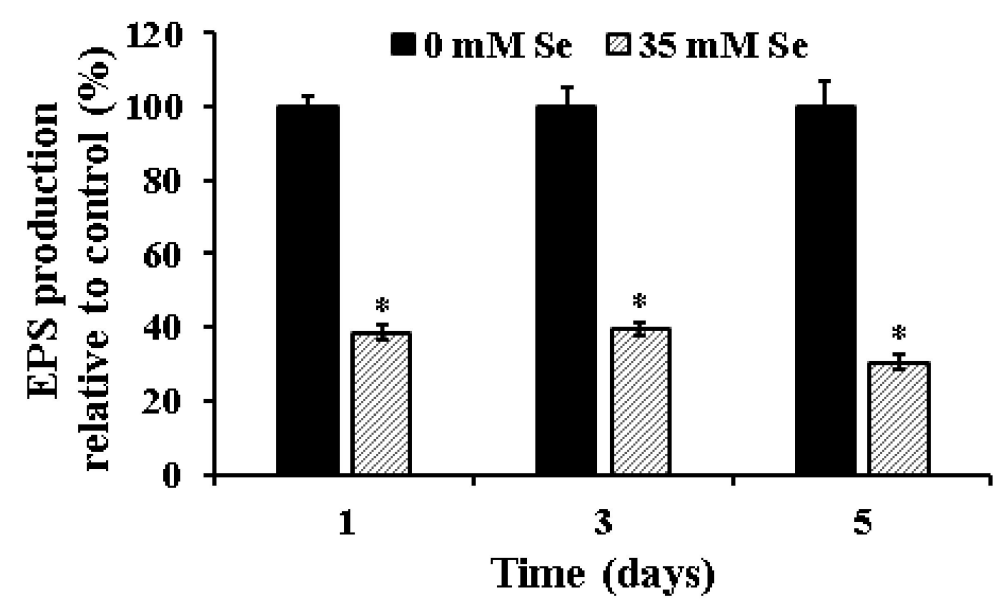

Figure 2. Effect of selenium on exopolysaccharide (EPS) production by UPEC. Sterile 96-well polystyrene tissue culture plates were inoculated with $200 \mu \mathrm{L}$ of the cell suspension $(\sim 6.0 \log \mathrm{CFU})$ followed by the addition of 0 or $35 \mathrm{mM}$ selenium. The plates were incubated at $37^{\circ} \mathrm{C}$. Following 1 , 3 , and 5 days of exposure, EPS production was assayed by staining the wells with $0.01 \%$ ruthenium red and recording the absorbance at $450 \mathrm{~nm}$. Data are represented as mean $\pm \mathrm{SEM}$. ${ }^{*}$ Treatments are significantly different from the control at $p \leq 0.05$. 


\subsection{Effect of Selenium on the Expression of Biofilm-Associated Genes in UPEC}

As in other bacteria, the transition of planktonic UPEC to a sessile, sedentary biofilm requires a precisely orchestrated and coordinated regulation of genes critical to biofilm formation [43]. Since incorporation of selenium at its SIC led to a significant reduction in UPEC biofilm formation in the absence of a bacteriostatic or bacteriocidal effect, we performed RT-qPCR on UPEC genes (fimA, fimH, papG, focA, $s f a S$ ) associated with biofilm formation and virulence to understand the underlying mechanism of action. These gene candidates were selected based on previous studies demonstrating their role in UPEC biofilm formation and virulence. For instance, in UPEC, the initial adhesion that is required to trigger biofilm formation is mediated by the Type I pilli $[4,36,44]$. The two major units of the type I pili are FimH and FimA encoded by the fim $H$ and fim $A$ genes, respectively $[45,46]$. With specific reference to biofilm formation, numerous studies have demonstrated the role of the FimH adhesion in mediating UPEC attachment to biotic and abiotic surfaces [47-49]. Further, UPEC fimH deletion mutants were found to be severely defective in pellicle formation when compared to the wild-type strain [50]. Similarly, fimA has been shown to be involved in the attachment of Gram-negative bacteria, including E. coli, to abiotic surfaces [51]. Towards this, Silva et al. [52] observed significant upregulation of fimA gene expression in E. coli during biofilm formation when compared to planktonic cells. In corroboration with these studies, a 2-3 fold reduction in fim $\mathrm{H}$ and fim $A$ expression was observed with selenium-treated UPEC when compared to the control. Therefore, the ability of selenium to inhibit biofilm formation could be attributed to the impaired initial adhesion process.

Similarly, a 4-10 fold reduction in focA, sfaS, and papG expression was also observed following selenium treatment of UPEC (Figure 3). These genes encoding for the type I pili, P (pap), F1C (focA), and S-fimbriae ( $\mathrm{ffaS}$ ) are considered to be important virulence factors for the induction of UTI and formation of biofilm [53-56]. A higher prevalence of sfaS (S-fimbriae) gene was observed for UPEC strains producing moderate to strong biofilms [57]. Similarly, Adamus-Bialek et al. [55] and Naves et al. [58] demonstrated that the virulence genes $s f a$, foc, and $p a p G$ were more common in strong biofilm-producing E. coli isolates. Hence, in addition to reducing EPS production, the inhibitory effect of selenium on UPEC biofilm formation could also be mediated by the downregulation of the above-mentioned genes. Also, it is important to note that these adhesins play a critical role in UPEC attachment, invasion, and colonization in the urinary tract [59]. Hence, besides inhibiting biofilm formation, selenium at the SIC level could also serve as an anti-virulence agent in attenuating the infectious nature of UPEC.

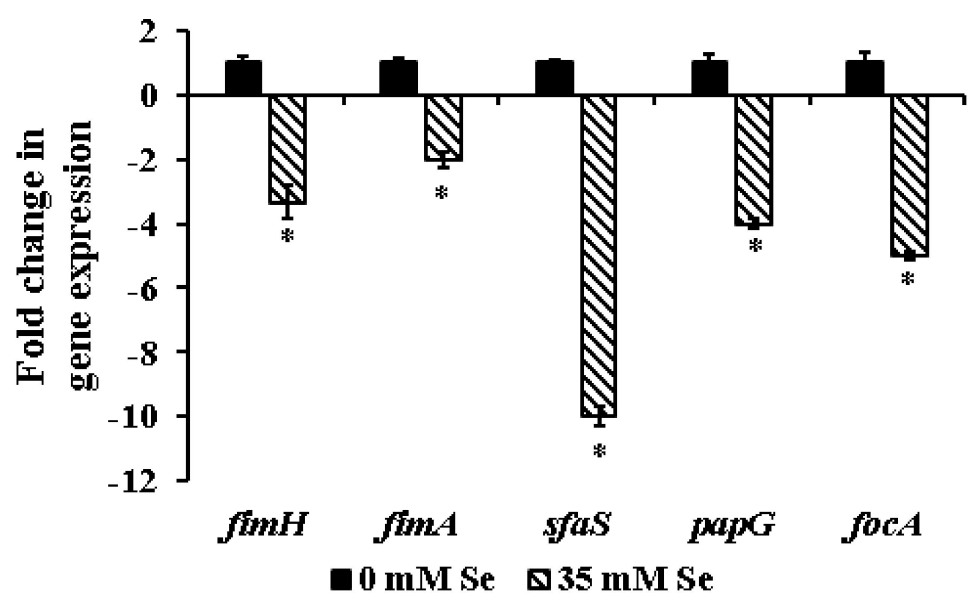

Figure 3. Effect of sub-inhibitory concentrations of selenium on the expression of biofilm genes in UPEC. Relative gene expression was assayed using the StepOne Plus Real Time PCR System. The data were normalized to the endogenous control and the level of candidate gene expression between selenium-treated and untreated samples was compared to study relative gene expression. * Treatments are significantly different from the control at $p \leq 0.05$. 


\subsection{Inactivation of Pre-Formed UPEC Biofilms on Urinary Catheters by Selenium}

Microbial biofilms are of significant public health concern given their reduced susceptibility to antimicrobial agents and their ability to cause infections in patients with indwelling medical devices $[16,32,60]$. The increased resistance to antimicrobials of biofilms can be attributed to the extensive ECM, reduced growth rates of biofilm-associated bacteria, and the protective environment within the biofilm [61]. The presence of ECM provides a significant hurdle to the diffusion of the antimicrobial into the biofilm, thereby limiting its contact and antimicrobial effect on the bacteria within the biofilm. Further, studies have shown that the EPS of P. aeruginosa can bind to tobramycin and limit the entry of the antibiotic into the biofilm, thus reducing its antimicrobial susceptibility [62]. Similar studies have demonstrated that antimicrobial metals, such as zinc and manganese, exhibit a reduced antibiofilm efficacy due to their decreased diffusion through the biofilm $[63,64]$. Hence, in the present study, higher concentrations of selenium (MIC and MBC) were employed in the biofilm inactivation studies.

As can be seen from Figure 4, treatment of preformed biofilms with selenium (45-85 mM) was effective in significantly killing fully formed UPEC biofilms on urinary catheters $(p<0.05)$. With the untreated control samples, approximately 5.5 and $5.9 \log$ CFU of UPEC was recovered from the catheter biofilms on day 1 and day 5, respectively. However, with selenium treatment, a dose-dependent antibiofilm effect was observed until the end of the study. Of the three concentrations tested, $85 \mathrm{mM}$ selenium (MBC) was found to be most effective with a greater than $5 \log (92 \%)$ reduction and complete inactivation of the UPEC biofilm on day 1 and day 3 of the study, respectively. Similarly, treatment with $60 \mathrm{mM}$ (MIC) and $45 \mathrm{mM}$ (sub-MIC) lead to an $\sim 5 \log$ reduction in biofilm populations by day 3 and day 5 , respectively. In addition to bacterial enumeration, SEM was performed to visualize the architecture and morphology of UPEC biofilms formed on urinary catheters. The SEM image of UPEC biofilm grown on urinary catheters is depicted in Figure 5A. These images confirm the presence of biofilm growth on the catheter pieces, where individual UPEC cells can be seen scattered over the matrix surface (Figure 5A). In addition, analysis of the cross-section and inner surface of the catheter samples revealed that the relative number of bacteria on the catheter pieces treated with selenium (Figure 5B) was significantly less compared to the untreated samples (Figure 5A).

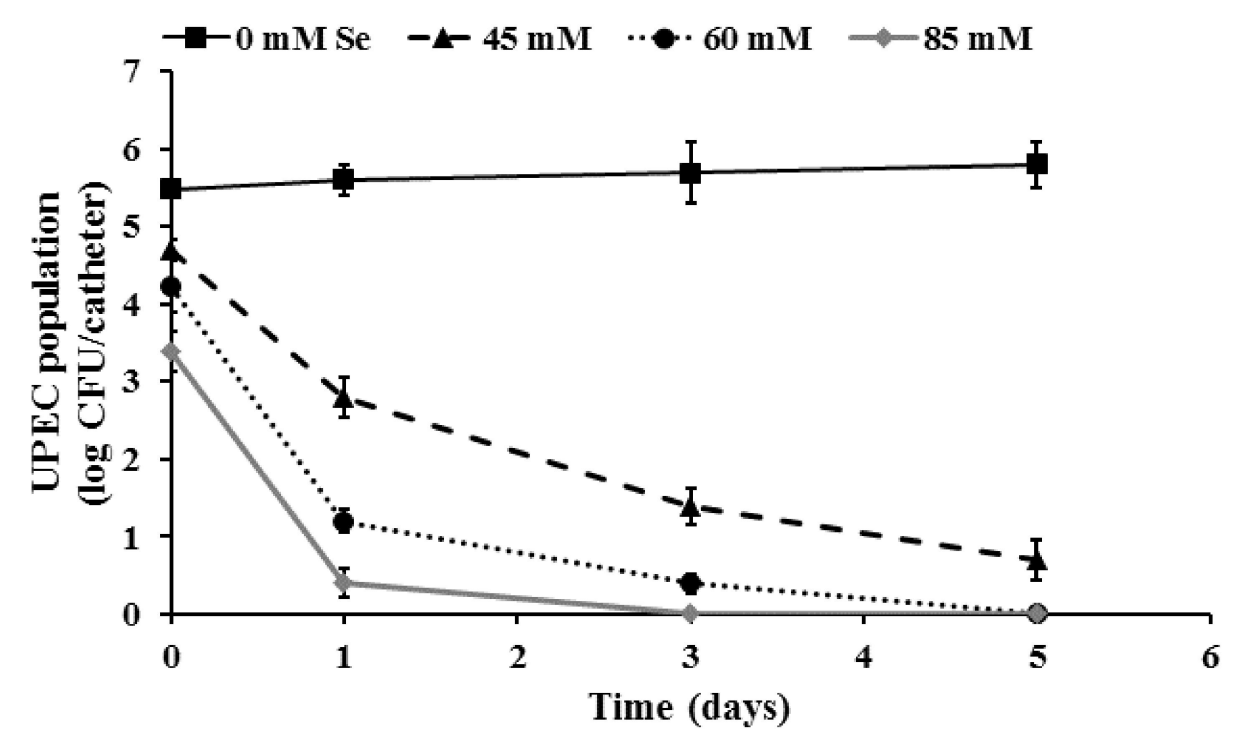

Figure 4. Inactivation of UPEC biofilm on urinary catheters by selenium. Catheter pieces $(3 \mathrm{~cm})$ were inoculated with UPEC ( $6.0 \log \mathrm{CFU})$ and incubated at $37^{\circ} \mathrm{C}$ for biofilm formation. The established biofilm was treated with $0,45,60$, and $85 \mathrm{mM}$ of selenium for an exposure time of $0,1,3$, and 5 days. Following exposure, the surviving cells in the biofilm were dispersed by sonication and enumerated. Data are represented as mean \pm SEM. Treatments are significantly different from the control at $p \leq 0.05$. 

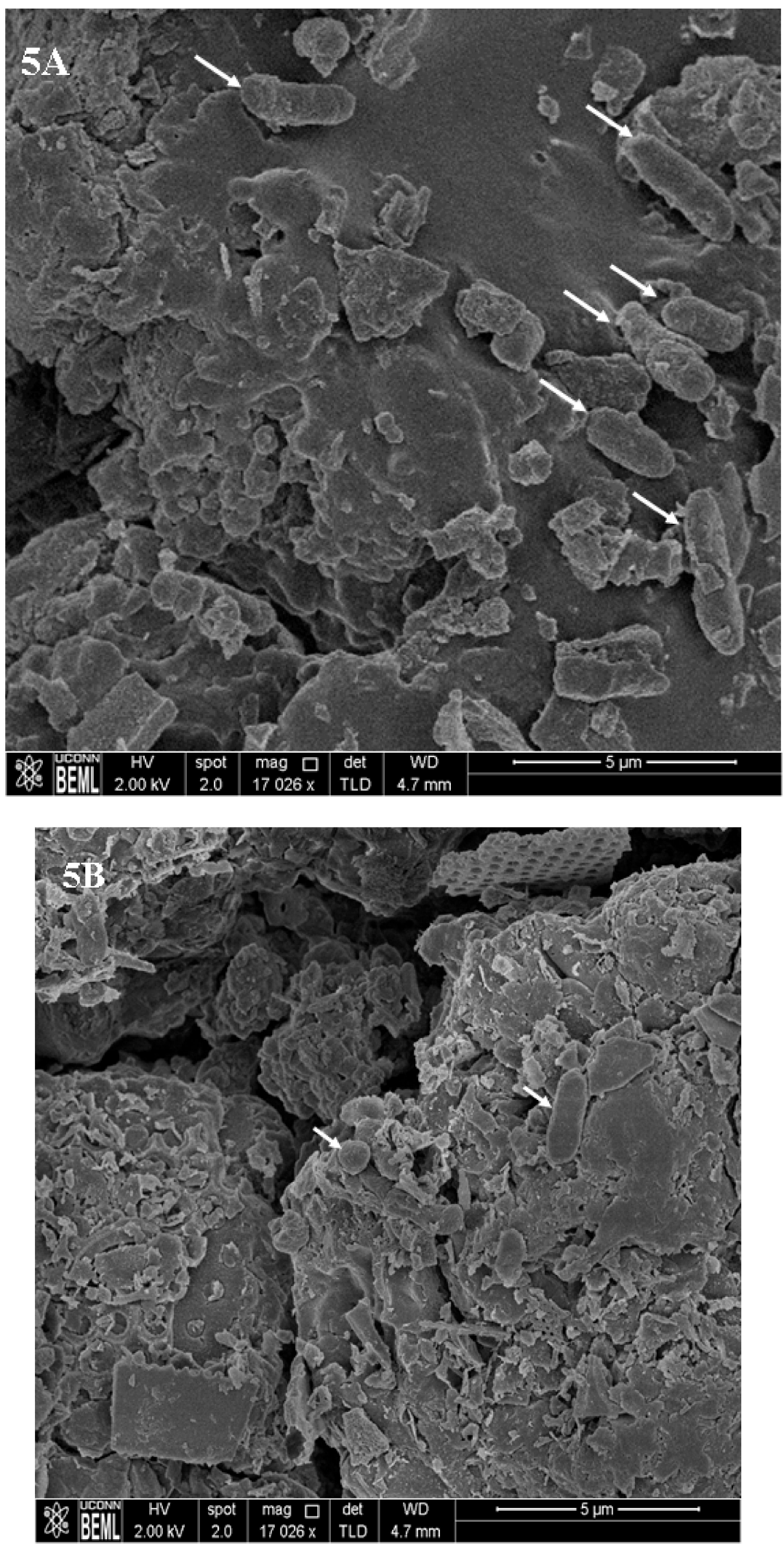

Figure 5. Ultrastructure images of UPEC biofilm on urinary catheters. Catheter pieces $(3 \mathrm{~cm})$ were inoculated with UPEC ( $\sim 6.0 \log \mathrm{CFU})$ and incubated at $37^{\circ} \mathrm{C}$ for biofilm formation. The established biofilm was treated with 0 and $85 \mathrm{mM}$ of selenium for an exposure time of 1 day. Following exposure, the catheter pieces were processed for SEM imaging. (A) Inoculated catheter without treatment, (B) inoculated catheter after selenium treatment. Arrows indicate UPEC cells on the catheter surface. 


\section{Materials and Methods}

\subsection{Bacterial Isolates and Growth Conditions}

Two UPEC strains (E. coli CFT073 and E. coli UMN 026) obtained from BEI resources (Manassas, VA, USA) were used in the study. All bacteriological media used in the study were procured from Difco (Becton, Dickson and Company, Franklin Lakes, NJ, USA). Each UPEC strain was cultured separately in Tryptic Soy broth (TSB) at $37^{\circ} \mathrm{C}$ overnight. After incubation, the cultures were centrifuged $(3000 \times g$, $12 \mathrm{~min}, 4^{\circ} \mathrm{C}$ ), and washed twice in phosphate-buffered saline (PBS, pH 7.0), separately. The pellet was then resuspended in PBS and used as the inoculum. Bacterial counts in the UPEC cultures were confirmed following serial dilution and plating on Tryptic Soy agar (TSA) plates followed by incubation at $37^{\circ} \mathrm{C}$ for $24 \mathrm{~h}$.

\subsection{Determining the SIC, MIC, and MBC of Se against EHEC}

The SIC (sub-inhibitory concentration), MIC (minimum inhibitory concentration), and MBC (minimum bactericidal concentration) of Se against UPEC were determined as previously described [59]. Briefly, sterile 24-well polystyrene tissue culture plates (Costar, Corning Incorporated, Corning, NY, USA) containing TSB ( $1 \mathrm{~mL} /$ well) were inoculated separately with $~ 5.5 \log$ CFU of UPEC followed by the addition of 0 to $5 \mu \mathrm{L}$ of $50 \%$ stock solutions of Se (sodium selenite, Sigma-Aldrich, St. Louis, MO, USA) with an increment of $0.5 \mu \mathrm{L}$. The plates were incubated at $37{ }^{\circ} \mathrm{C}$ for $24 \mathrm{~h}$, and bacterial growth was determined by culturing on TSA plates. The highest concentration of Se that did not inhibit bacterial growth after $24 \mathrm{~h}$ of incubation when compared to the control samples was selected as the SIC for this study. The lowest concentration of Se that inhibited bacterial growth after incubation was taken as the MIC of the treatment and the lowest concentration of Se that reduced UPEC population by $\sim 5.0 \log \mathrm{CFU} / \mathrm{mL}$ after incubation at $37^{\circ} \mathrm{C}$ for $24 \mathrm{~h}$ was taken as the $\mathrm{MBC}$.

\subsection{Inhibition of UPEC Biofilm Formation on Urinary Catheters by Selenium}

The efficacy of selenium to inhibit UPEC biofilm formation on urinary catheters was determined according to a previously published protocol [20,65]. Latex 12Fr Foley urinary catheter (AtHomeMedical, Morris Plains, NJ, USA) was cut into 3-cm pieces. Each catheter piece was sealed at one end, filled with $1 \mathrm{~mL}$ of bacterial culture ( $5.5 \log \mathrm{CFU})$, and sealed at the other end. The catheter pieces were then incubated at $37^{\circ} \mathrm{C}$ for $30 \mathrm{~min}$ to facilitate UPEC attachment to the catheter luminal surface. Following incubation, the catheter pieces were washed with sterile PBS to remove unattached cells and transferred to sterile tubes containing $10 \mathrm{~mL}$ TSB with $0 \%$ (control) or $0.6 \%$ (35 mM) selenium. The catheter pieces were then incubated statically at $37{ }^{\circ} \mathrm{C}$ for 5 days to facilitate biofilm formation. On days $0,1,3$, and 5 , the biofilm-associated UPEC population was determined after dislodging the biofilm from the luminal surface. This was achieved by vortexing the catheter pieces in separate tubes containing $10 \mathrm{~mL}$ of PBS for $1 \mathrm{~min}$ followed by sonication at $40 \mathrm{KHz}$ for $5 \mathrm{~min}$ in a bath sonicator (Branson, North Olmstead, OH, USA). After sonication, viable bacterial counts in PBS from each tube were enumerated after serial dilution (1:10 in PBS) and plating on duplicate TSA plates [20,66]. Three catheter pieces were included per treatment at each sampling time and the experiment was repeated three times.

\subsection{Effect of Se on UPEC Exopolysaccharide (EPS) Production}

The efficacy of selenium in reducing EPS production in UPEC biofilms was determined by ruthenium red staining assay [67]. For the assay, sterile 96-well polystyrene tissue culture plates (Costar) were inoculated with $200 \mu \mathrm{L}(\sim 5.5 \log$ CFU) of overnight, PBS-washed UPEC cultures followed by the addition of the SIC of selenium. The plates were incubated at $37{ }^{\circ} \mathrm{C}$ for 5 days. After 1,3 , and 5 days of incubation, the biofilms developed were scraped and washed with PBS followed by the addition of $200 \mu \mathrm{L}$ of aqueous $0.01 \%$ ruthenium red (Sigma-Aldrich) to each well and incubation at $25{ }^{\circ} \mathrm{C}$ for $60 \mathrm{~min}$. The optical density $(450 \mathrm{~nm})$ of the residual stain was then measured using 
a synergy HT multi-mode microplate reader (BioTek, Winooski, VT, USA). The amount of dye bound to the biofilm was determined by the formula $\mathrm{OD}_{\mathrm{BF}}=\mathrm{OD}_{\mathrm{B}}-\mathrm{OD}_{\mathrm{S}}\left(\mathrm{OD}_{\mathrm{BF}}\right.$ : optical density $(450 \mathrm{~nm})$ of biofilms; $\mathrm{OD}_{\mathrm{B}}$ : optical density $(450 \mathrm{~nm})$ of blanks; $\mathrm{OD}_{\mathrm{S}}$ : optical density $(450 \mathrm{~nm})$ of the residual stain collected from sample wells). Wells without biofilms added with $200 \mu \mathrm{L}$ of ruthenium red stain acted as blanks [68].

\subsection{Effect of Selenium on the Expression of UPEC Biofilm-Associated Genes}

The effect of selenium on the transcription of UPEC genes required for biofilm formation and virulence (fim $H$, fim $A, s f a S$, pep $G$, and $f o c A$ ) was investigated by using real-time quantitative PCR (RT-qPCR) [61,69]. Each UPEC strain was grown separately with or without the SIC of selenium at $37^{\circ} \mathrm{C}$ in TSB to mid-log phase in sterile 12-well polystyrene plates. Total RNA was extracted using the RNeasy RNA isolation kit (Qiagen, Valencia, CA, USA). Complementary DNA (cDNA) was synthesized using the iscript cDNA synthesis kit (Biorad, Hercules, CA, USA) and used as the template for RT-qPCR. The amplification product was detected using SYBR Green reagents (Biorad). Relative gene expression was determined by the comparative critical threshold $\left(2^{-\Delta \Delta C t}\right)$ value method using a StepOnePlus ${ }^{\mathrm{TM}}$ Real Time PCR system (Applied Biosystems, Carlsbad, CA, USA) and expressed as fold change in expression relative to controls. Data were normalized to the endogenous control (16S rRNA) and the level of candidate gene expression between control samples (not exposed to selenium) and treated samples (exposed to the SIC of selenium) was compared to study the effect of selenium on the expression of each biofilm-associated gene. Gene specific primers were used based on published literature [59], and 16S rRNA gene was used as a housekeeping gene or endogenous control.

\subsection{Inactivation of Preformed UPEC Biofilms on Urinary Catheters by Selenium}

The efficacy of selenium for inactivating fully formed UPEC biofilms on catheters was determined as previously described [20,66]. Latex 12Fr Foley urinary catheters were inoculated with UPEC as described under Section 3.3. Following inoculation, the catheter pieces were sealed and incubated at $37^{\circ} \mathrm{C}$ to facilitate UPEC biofilm formation. After 5 days, each catheter piece was washed with sterile PBS to remove unattached cells, sealed at one end, filled with $1 \mathrm{~mL}$ of sterile PBS (control) or PBS containing $0.75 \%(45 \mathrm{mM}), 1 \%(60 \mathrm{mM})$, and $1.5 \%(85 \mathrm{mM})$ of selenium, sealed at the other end, and incubated at $37^{\circ} \mathrm{C}$ for 5 days. On days $0,1,3$, and 5 , biofilm-associated UPEC population was determined as described previously. Three catheter pieces were included per treatment at each sampling time and the experiment was repeated three times.

\subsection{Scanning Electron Microscopy (SEM)}

E. coli CFT073 biofilm formation and inactivation by selenium on urinary catheters was examined by SEM [70]. UPEC biofilms were formed on catheter pieces as described previously. Following biofilm formation, the inoculated catheter pieces were washed with sterile phosphate-buffered saline (PBS) to dislodge the loosely attached and unattached bacterial cells. Subsequently, they were treated with either $2 \%(110 \mathrm{mM})$ selenium or sterile PBS for 1 day at $37{ }^{\circ} \mathrm{C}$. Samples were then fixed in glutaraldehyde-paraformaldehyde-cacodylate buffer $(\mathrm{pH} 7)$ at $4{ }^{\circ} \mathrm{C}$ for $90 \mathrm{~min}$. Following fixation, catheters were washed with $0.1 \mathrm{M} \mathrm{Na}$ cacodylate buffer $(\mathrm{pH} 7)$ and post-fixed in $1 \%$ osmium tetroxide at $4{ }^{\circ} \mathrm{C}$ overnight. The catheters were then rinsed twice for $15 \mathrm{~min}$ in distilled water, then dehydrated in serial concentrations of ethanol (30\%,50\%, 70\%, 95\%, 100\%, 100\% ETOH, 15 min each), and critical point dried (Critical Point Dryer 931GL, Tousimis, Rockville. MD, USA). The dried catheter samples were then mounted on the SEM stub using silver paint and sputter coated with gold/palladium and examined using a scanning electron microscope (Nova NanoSEM 450, FEI, Hillsboro, OR, USA).

\subsection{Statistical Analysis}

The entire study was repeated three times with triplicate samples with a completely randomized design. Data were analyzed using the PROC GLM procedure of SAS (v 9.2, The SAS Institute, Cary, 
NC, USA) and differences between the means were compared using the least significant difference test. Differences were considered significant when the $p$ value was $<0.05$.

\section{Conclusions}

In conclusion, our study demonstrates that selenium at lower concentrations (SIC) was effective in preventing UPEC biofilm formation on urinary catheters. Further, this inhibitory effect of selenium was found to be associated with a reduction in EPS production and the expression of UPEC genes involved in biofilm formation. Additionally, at high concentrations (MBC), selenium was effective in inactivating preformed UPEC biofilms on urinary catheters. These results suggest that selenium could be potentially used as an antimicrobial catheter lock solution to control UPEC biofilms on indwelling devices. Despite its antibiofilm effect, given the concerns for potential side effects associated with the administration of selenium, additional experiments are needed to determine its safety and to evaluate the efficacy of selenium in comparison with other antibiofilm therapies in vitro and in vivo.

Author Contributions: M.A.A. conceived and designed the experiments; A.N., M.S.N., and M.S.M. performed the experiments; M.S.N. analyzed the data; M.A.A. wrote and revised the manuscript.

Conflicts of Interest: The authors declare no conflict of interest.

\section{References}

1. Terlizzi, M.E.; Gribaudo, G.; Maffei, M.E. UroPathogenic Escherichia coli (UPEC) infections: Virulence factors, bladder responses, antibiotic, and non-antibiotic antimicrobial strategies. Front. Microbiol. 2017, 8, 1566. [CrossRef] [PubMed]

2. Foxman, B. Urinary tract infection syndromes: Occurrence, recurrence, bacteriology, risk factors, and disease burden. Infect. Dis. Clin. N. Am. 2014, 28, 1-13. [CrossRef] [PubMed]

3. Parker, V.; Giles, M.; Graham, L.; Suthers, B.; Watts, W.; O’Brien, T.; Searles, A. Avoiding inappropriate urinary catheter use and catheter-associated urinary tract infection (CAUTI): A pre-post control intervention study. BMC Health Serv. Res. 2017, 17, 314. [CrossRef] [PubMed]

4. Amalaradjou, M.A.; Venkitanarayanan, K. Role of bacterial biofilms in catheter-associated urinary tract infections (CAUTI) and strategies for their control. In Recent Advances in the Field of Urinary Tract Infections; Nelius, T., Ed.; IntechOpen: London, UK, 2013; pp. 55-88.

5. Meddings, J.; Reichert, H.; McMahon, L.F., Jr. Challenges and proposed improvements for reviewing symptoms and catheter use to identify National Healthcare Safety Network catheter-associated urinary tract infections. Am. J. Infect. Control 2014, 42, S236-S241. [CrossRef] [PubMed]

6. Foxman, B. The epidemiology of urinary tract infection. Nat. Rev. Urol. 2010, 7, 653-660. [CrossRef] [PubMed]

7. Centers for Disease Control and Prevention (CDC). Catheter-Associated Urinary Tract Infection (CAUTI). 2018. Available online: https://www.cdc.gov/nhsn/pdfs/pscmanual/7psccauticurrent.pdf (accessed on 8 April 2018).

8. Warren, J.W. Catheter-associated urinary tract infections. Int. J. Antimicrob. Agents 2001, 17, $299-303$. [CrossRef]

9. Flores-Mireles, A.L.; Walker, J.N.; Caparon, M.; Hultgren, S.J. Urinary tract infections: Epidemiology, mechanisms of infection and treatment options. Nat. Rev. Microbiol. 2015, 13, 269-284. [CrossRef] [PubMed]

10. Chenoweth, C.E.; Gould, C.V.; Saint, S. Diagnosis, management, and prevention of catheter-associated urinary tract infections. Infect. Dis. Clin. N. Am. 2014, 28, 105-119. [CrossRef] [PubMed]

11. Hollenbeak, C.S.; Schilling, A.L. The attributable cost of catheter-associated urinary tract infections in the United States: A systematic review. Am. J. Infect. Control 2018. [CrossRef] [PubMed]

12. Bagshaw, S.M.; Laupland, K.B. Epidemiology of intensive care unit-acquired urinary tract infections. Curr. Opin. Infect. Dis. 2006, 19, 67-71. [CrossRef] [PubMed]

13. Guggenbichler, J.P.; Assadian, O.; Boeswald, M.; Kramer, A. Incidence and clinical implication of nosocomial infections associated with implantable biomaterials-Catheters, ventilator-associated pneumonia, urinary tract infections. GMS Krankenhhyg Interdiszip 2011, 6, Doc18. [CrossRef] [PubMed] 
14. Ronald, A. The etiology of urinary tract infection: Traditional and emerging pathogens. Dis. Mon. 2003, 49, 71-82. [CrossRef] [PubMed]

15. Eberly, A.R.; Floyd, K.A.; Beebout, C.J.; Colling, S.J.; Fitzgerald, M.J.; Stratton, C.W.; Schmitz, J.E.; Hadjifrangiskou, M. Biofilm formation by uropathogenic Escherichia coli is favored under oxygen conditions that mimic the bladder environment. Int. J. Mol. Sci. 2017, 18, 2077. [CrossRef] [PubMed]

16. Nicolle, L.E. Catheter associated urinary tract infections. Antimicrob. Resist. Infect. Control 2014, 3, 23. [CrossRef] [PubMed]

17. Nickel, J.C.; Gristina, A.G.; Costerton, J.W. Electron microscopic study of an infected Foley catheter. Can. J. Surg. 1985, 28, 50-51. [PubMed]

18. Nickel, J.C.; Downey, J.A.; Costerton, J.W. Ultrastructural study of microbiologic colonization of urinary catheters. Urology 1989, 34, 284-291. [CrossRef]

19. Ohkawa, M.; Sugata, T.; Sawaki, M.; Nakashima, T.; Fuse, H.; Hisazumi, H. Bacterial and crystal adherence to the surfaces of indwelling urethral catheters. J. Urol. 1990, 143, 717-721. [CrossRef]

20. Amalaradjou, M.A.; Narayanan, A.; Baskaran, S.A.; Venkitanarayanan, K. Antibiofilm effect of trans-cinnamaldehyde on uropathogenic Escherichia coli. J. Urol. 2010, 184, 358-363. [CrossRef] [PubMed]

21. Estevam, E.C.; Witek, K.; Faulstich, L.; Nasim, M.J.; Latacz, G.; Dominguez-Alvarez, E.; Kiec-Kononowicz, K.; Demasi, M.; Handzlik, J.; Jacob, C. Aspects of a distinct cytotoxicity of selenium salts and organic selenides in living cells with possible implications for drug design. Molecules 2015, 20, 13894-13912. [CrossRef] [PubMed]

22. Sunde, R.A. Selenium. In Modern Nutrition in Health and Disease, 11th ed.; Ross, A.C., Caballero, B., Cousins, R.J., Tucker, K.L., Ziegler, T.R., Eds.; Lippincott Williams \& Wilkins: Philadelphia, PA, USA, 2012; pp. 225-237.

23. Wang, Q.; Larese-Casanova, P.; Webster, T.J. Inhibition of various Gram-positive and Gram-negative bacteria growth on selenium nanoparticle coated paper towels. Int. J. Nanomed 2015, 10, 2885-2894. [CrossRef]

24. Vasić, S.; Radojević, I.; Pešić, N.; Čomić, L. Influence of sodium selenite on the growth of selected bacteria species and their sensitivity to antibiotics. Kragujev. J. Sci. 2011, 33, 55-61.

25. Kumar, B.S.; Tiwari, S.K.; Manoj, G.; Kunwar, A.; Amrita, N.; Sivaram, G.; Abid, Z.; Ahmad, A.; Khan, A.A.; Priyadarsini, K.I. Anti-unlcer and antimicrobial activities of sodium selenite against Helicobacter pylori: In vitro and in vivo evaluation. Scand. J. Infect. Dis. 2010, 42, 266-274. [CrossRef] [PubMed]

26. Alam, M.F.; Safhi, M.M.; Moni, S.S.; Jabeen, A. In Vitro antibacterial spectrum of sodium selenite against selected human pathogenic bacterial strains. Scientifica (Cairo) 2016, 2016, 9176273. [CrossRef]

27. Khiralla, G.M.; El-Deeb, B.A. Antimicrobial and antibiofilm effects of selenium nanoparticles on some foodborne pathogens. LWT-Food Sci. Technol. 2015, 63, 1001-1007. [CrossRef]

28. Tran, P.A.; Webster, T.J. Selenium nanoparticles inhibit Staphylococcus aureus growth. Int. J. Nanomed. 2011, 6, 1553-1558. [CrossRef]

29. Denstedt, J.D.; Wollin, T.A.; Reid, G. Biomaterials used in urology: Current issues of biocompatibility, infection, and encrustation. J. Endourol. 1998, 12, 493-500. [CrossRef] [PubMed]

30. Pratt, L.A.; Kolter, R. Genetic analysis of Escherichia coli biofilm formation: Roles of flagella, motility, chemotaxis and type I pili. Mol. Microbiol. 1998, 30, 285-293. [CrossRef] [PubMed]

31. Trautner, B.W.; Darouiche, R.O. Role of biofilm in catheter-associated urinary tract infection. Am. J. Infect. Control 2004, 32, 177-183. [CrossRef] [PubMed]

32. Donlan, R.M. Biofilms and device-associated infections. Emerg. Infect. Dis. 2001, 7, 277-281. [CrossRef] [PubMed]

33. Kim, H.S.; Park, H.D. Ginger extract inhibits biofilm formation by Pseudomonas aeruginosa PA14. PLoS ONE 2013, 8, e76106. [CrossRef] [PubMed]

34. Nair, M. Controlling Enterohemorrhagic E. coli O157:H7 Using Selenium and Rutin. Ph.D. Thesis, University of Connecticut, Storrs, CT, USA, 2017. 1552. Available online: https://opencommons.uconn.edu/ dissertations/1552/ (accessed on 8 April 2018).

35. Bhattaram, V. Investigating the Potential of Essential Minerals for Controlling Vibrio cholerae. Ph.D. Thesis, University of Connecticut, Storrs, CT, USA, 2017. 1498. Available online: https:/ / opencommons.uconn.edu/ cgi/viewcontent.cgi?article $=7707 \&$ context=dissertations (accessed on 8 April 2018).

36. Yang, X.; Sha, K.; Xu, G.; Tian, H.; Wang, X.; Chen, S.; Wang, Y.; Li, J.; Chen, J.; Huang, N. Subinhibitory concentrations of allicin decrease uropathogenic Escherichia coli (UPEC) biofilm formation, adhesion ability, and swimming motility. Int. J. Mol. Sci. 2016, 17, 979. [CrossRef] [PubMed] 
37. Sutherland, I.W. The biofilm matrix-An immobilized but dynamic microbial environment. Trends Microbiol. 2001, 9, 222-227. [CrossRef]

38. Devraj, A.; Justice, A.A.; Bakaletz, L.O.; Goodman, S.D. DNABII proteins play a central role in UPEC biofilm structure. Mol. Microbiol. 2015, 96, 1119-1135. [CrossRef] [PubMed]

39. Wang, X.; Preston, J.F., 3rd; Romeo, T. The pgaABCD locus of Escherichia coli promotes the synthesis of a polysaccharide adhesin required for biofilm formation. J. Bacteriol. 2004, 186, 2724-2734. [CrossRef] [PubMed]

40. Vuong, C.; Kocianova, S.; Voyich, J.M.; Yao, Y.; Fischer, E.R.; DeLeo, F.R.; Otto, M. A crucial role for exopolysaccharide modification in bacterial biofilm formation, immune evasion, and virulence. J. Biol. Chem. 2004, 279, 54881-54886. [CrossRef] [PubMed]

41. Fluckiger, U.; Ulrich, M.; Steinhuber, A.; Doring, G.; Mack, D.; Landmann, R.; Goerke, C.; Wolz, C. Biofilm formation, icaADBC transcription, and polysaccharide intercellular adhesin synthesis by staphylococci in a device-related infection model. Infect. Immun. 2005, 73, 1811-1819. [CrossRef] [PubMed]

42. Hayat, S.; Sabri, A.N.; McHugh, T.D. Chloroform extract of turmeric inhibits biofilm formation, EPS production and motility in antibiotic resistant bacteria. J. Gen. Appl. Microbiol. 2018, 63, 325-338. [CrossRef] [PubMed]

43. Niba, E.T.; Naka, Y.; Nagase, M.; Mori, H.; Kitakawa, M. A genome-wide approach to identify the genes involved in biofilm formation in E. coli. DNA Res. 2007, 14, 237-246. [CrossRef] [PubMed]

44. Blumer, C.; Kleefeld, A.; Lehnen, D.; Heintz, M.; Dobrindt, U.; Nagy, G.; Michaelis, K.; Emody, L.; Polen, T.; Rachel, R.; et al. Regulation of type 1 fimbriae synthesis and biofilm formation by the transcriptional regulator LrhA of Escherichia coli. Microbiology 2005, 151, 3287-3298. [CrossRef] [PubMed]

45. Gally, D.L.; Leathart, J.; Blomfield, I.C. Interaction of FimB and FimE with the fim switch that controls the phase variation of type 1 fimbriae in Escherichia coli K-12. Mol. Microbiol. 1996, 21, 725-738. [CrossRef] [PubMed]

46. Hatt, J.K.; Rather, P.N. Role of bacterial biofilms in urinary tract infections. Curr. Top. Microbiol. Immunol. 2008, 322, 163-192. [PubMed]

47. Hung, C.S.; Bouckaert, J.; Hung, D.; Pinkner, J.; Widberg, C.; DeFusco, A.; Auguste, C.G.; Strouse, R.; Langermann, S.; Waksman, G.; et al. Structural basis of tropism of Escherichia coli to the bladder during urinary tract infection. Mol. Microbiol. 2002, 44, 903-915. [CrossRef] [PubMed]

48. Harber, M.J.; Mackenzie, R.; Asscher, A.W. A rapid bioluminescence method for quantifying bacterial adhesion to polystyrene. J. Gen. Microbiol. 1983, 129, 621-632. [CrossRef] [PubMed]

49. Chen, S.L.; Hung, C.S.; Pinkner, J.S.; Walker, J.N.; Cusumano, C.K.; Li, Z.; Bouckaert, J.; Gordon, J.I.; Hultgren, S.J. Positive selection identifies an in vivo role for FimH during urinary tract infection in addition to mannose binding. Proc. Natl. Acad. Sci. USA 2009, 106, 22439-22444. [CrossRef] [PubMed]

50. Hung, C.; Zhou, Y.; Pinkner, J.S.; Dodson, K.W.; Crowley, J.R.; Heuser, J.; Chapman, M.R.; Hadjifrangiskou, M.; Henderson, J.P.; Hultgren, S.J. Escherichia coli biofilms have an organized and complex extracellular matrix structure. MBio 2013, 4, e00645-13. [CrossRef] [PubMed]

51. Berne, C.; Ducret, A.; Hardy, G.G.; Brun, Y.V. Adhesins involved in attachment to abiotic surfaces by Gram-Negative bacteria. Microbiol. Spectr. 2015, 3, 10. [CrossRef] [PubMed]

52. Silva, V.O.; Soares, L.O.; Silva Junior, A.; Mantovani, H.C.; Chang, Y.F.; Moreira, M.A. Biofilm formation on biotic and abiotic surfaces in the presence of antimicrobials by Escherichia coli isolates from cases of bovine mastitis. Appl. Environ. Microbiol. 2014, 80, 6136-6145. [CrossRef] [PubMed]

53. Riegman, N.; Kusters, R.; Van Veggel, H.; Bergmans, H.; Van Bergen en Henegouwen, P.; Hacker, J.; Van Die, I. F1C fimbriae of a uropathogenic Escherichia coli strain: Genetic and functional organization of the foc gene cluster and identification of minor subunits. J. Bacteriol. 1990, 172, 1114-1120. [CrossRef] [PubMed]

54. Bergsten, G.; Wullta, B.; Svanborg, C. Escherichia coli, fimbriae, bacterial persistence and host response induction in the human urinary tract. Int. J. Med. Microbiol. 2005, 295, 487-502. [CrossRef] [PubMed]

55. Adamus-Bialek, W.; Kubiak, A.; Czerwonka, G. Analysis of uropathogenic Escherichia coli biofilm formation under different growth conditions. Acta Biochim. Pol. 2015, 62, 765-771. [CrossRef] [PubMed]

56. Jahandeh, N.; Ranjbar, R.; Behzadi, P.; Behzadi, E. Uropathogenic Escherichia coli virulence genes: Invaluable approaches for designing DNA microarray probes. Cent. Eur. J. Urol. 2015, 68, 452-458. [CrossRef]

57. Zamani, H.; Salehzadeh, A. Biofilm formation in uropathogenic Escherichia coli: Association with adhesion factor genes. Turk. J. Med. Sci. 2018, 48, 162-167. [CrossRef] [PubMed] 
58. Naves, P.; del Prado, G.; Huelves, L.; Gracia, M.; Ruiz, V.; Blanco, J.; Dahbi, G.; Blanco, M.; Ponte Mdel, C.; Soriano, F. Correlation between virulence factors and in vitro biofilm formation by Escherichia coli strains. Microb. Pathog. 2008, 45, 86-91. [CrossRef] [PubMed]

59. Amalaradjou, M.A.; Narayanan, A.; Venkitanarayanan, K. Trans-cinnamaldehyde decreases attachment and invasion of uropathogenic Escherichia coli in urinary tract epithelial cells by modulating virulence gene expression. J. Urol. 2011, 185, 1526-1531. [CrossRef] [PubMed]

60. Soto, S.M.; Smithson, A.; Horcajada, J.P.; Martinez, J.A.; Mensa, J.P.; Vila, J. Implication of biofilm formation in the persistence of urinary tract infection caused by uropathogenic Escherichia coli. Clin. Microbiol. Infect. 2006, 12, 1034-1036. [CrossRef] [PubMed]

61. Donlan, R.M. Role of biofilms in antimicrobial resistance. ASAIO J. 2000, 46, 46-S52. [CrossRef]

62. Hoyle, B.D.; Wong, C.K.; Costerton, J.W. Disparate efficacy of tobramycin on $\mathrm{Ca}^{2+}-, \mathrm{Mg}^{2+}-$, and HEPES-treated Pseudomonas aeruginosa biofilms. Can. J. Microbiol. 1992, 38, 1214-1218. [CrossRef] [PubMed]

63. Hu, Z.; Jin, J.; Abruna, H.D.; Houston, P.L.; Hay, A.G.; Ghiorse, W.C.; Shuler, M.L.; Hidalgo, G.; Lion, L.W. Spatial distributions of copper in microbial biofilms by scanning electrochemical microscopy. Environ. Sci. Technol. 2007, 41, 936-941. [CrossRef] [PubMed]

64. Harrison, J.J.; Ceri, H.; Turner, R.J. Multimetal resistance and tolerance in microbial biofilms. Nat. Rev. Microbiol. 2007, 5, 928-938. [CrossRef] [PubMed]

65. Trautner, B.W.; Hull, R.A.; Darouiche, R.O. Escherichia coli 83972 inhibits catheter adherence by a broad spectrum of uropathogens. Urology 2003, 61, 1059-1062. [CrossRef]

66. Narayanan, A.; Nair, M.S.; Karumathil, D.P.; Baskaran, S.A.; Venkitanarayanan, K.; Amalaradjou, M.A. Inactivation of Acinetobacter baumannii biofilms on polystyrene, stainless steel, and urinary catheters by octenidine dihydrochloride. Front. Microbiol. 2016, 7, 847. [CrossRef] [PubMed]

67. Borucki, M.K.; Peppin, J.D.; White, D.; Loge, F.; Call, D.R. Variation in biofilm formation among strains of Listeria monocytogenes. Appl. Environ. Microbiol. 2003, 69, 7336-7342. [CrossRef] [PubMed]

68. Zameer, F.; Gopal, S.; Krohne, G.; Kreft, J. Development of a biofilm model for Listeria monocytogenes EGD-e. World J. Microbiol. Biotechnol. 2010, 26, 1143-1147. [CrossRef]

69. Lee, J.H.; Cho, H.S.; Joo, S.W.; Chandra Regmi, S.; Kim, J.A.; Ryu, C.M.; Ryu, S.Y.; Cho, M.H.; Lee, J. Diverse plant extracts and trans-resveratrol inhibit biofilm formation and swarming of Escherichia coli O157:H7. Biofouling 2013, 29, 1189-1203. [CrossRef] [PubMed]

70. Djeribi, R.; Bouchloukh, W.; Jouenne, T.; Menaa, B. Characterization of bacterial biofilms formed on urinary catheters. Am. J. Infect. Control 2012, 40, 854-859. [CrossRef] [PubMed] 